thickened, so that they are more or less obliteruted. A gumma may therefore be looked upon as a jortion of cicatricial tissue which has become necrosed owiug to its vascular supply being cut off by the obliteration of the bloodvessels; destruction of the cellular elements and caseous degeneration quickly follow a diminution of the nutritive supply in the central part of the growtl, which is, of course, farthest removed. The products of this degeneration are then absorbed, and the tumour gradually dimmishes in size, ultimately becoming a mere radiating cicatrix in the hepatic tissue. If these growths are situated near the surface, it will be readily understood that, owing to the contractions of the cicatricial tissue, puckerings must necessarily follow, and between the deep furrows thus caused the glandular structure, which is most probably hypertrophied, projects above the surface, forming more or less globular eminences, which give the syphilitic liver its peculiar chardcter. The absorption of these degenerated tumours is a subject of great practical importance, as by this means the infection of other organs is possibly produced.

The third variety of hepatic tumours, "the cavernous," to which I propose to refer, is one of no clinical import ance. They vary in size from a pea to that of a walnut, are multiple, sharply defined, and filled with erectile tissue. At first sight they appear to be mere extravasations of blood; but if a stream of water be aliowed to flow over them the blood present is washed out as from a sponge, and a grey-coloured fibrous network remains. Near the capsule these tumours have a livid appearance ; they are never found in children, always when present occurring in adults. The tumours are composed of a network of connective tissue, in the cavities of which the blood circulates; that the blood does circulate is proved by the absence of all blood pigment, for if present this would of course at once inclicate an extra. vasation. Examined under the microscope, a trabecula will be seen to consist of fibrous tissue, with spindle-shaped cells scattered here and there throughout its structure. By some these cells are supposed to be involuntary muscular fibre cells, but I think they are nothing more than ordinary connective-tissue corpuscles, and on its surface a layer of endothelium. There is also an abundance of elastic tissue fibres surrounding and traversing the spaces. At the periphery of the tumour a liyer of connective tissue is seen separating it from the liver substance proper, which layer sends out processes of convective tissue between adjacent lobules; as this tissue increases in amount and extends along the portal canals it naturally produces pressure upon the hepatic parenchyna and lobular vessels; the former slowly atrophy and the latter become compressed, the hepatic vein collapses, ultimately becoming the centre of the growth as the tissue gradually encroaches on the lobule converging towards the vein from all sides. The tissue then undergoes great contraction in a direction at right angles to the long axis of the bloodvessels, giving rise to the dilated chambers which are so characteristic of this growth. The cavernous tumour is therefore nothing more than an increase of interlobular connective tissue followed by what Rindfleisch calls cavernous metamorphosis. It must not be supposed that the chambers are mere dilatations of pre-existing bloodvessels. In this respect the cavernous tumour differs widely from that of phlebitis ohliterans. In this disease one of the larger portal vessels becomes occluded, but the same amount of blood being sent to the liver into the smaller vessels these must dilate to receive it, which they do enormously, pressure is thus brought to bear on the hepatic cells, which ultimately disappear, whilst in the vessels themselves there are large quantities of blood cells. The lacunie, of which cavernous tumours are composed, Virchow has shown can only be filled by injecting through the portal vein or hepatic artery, and not by injections made through the hepatic vein; this seems to be easily explained by remembering the site of the growth, the portal canals contain branches only of the portal vein and hepatic artery, and a tumour arising bere would naturally obtain its blood-supply from these sources.

The last tumour on which I will remark in Group 1 is what I have called the typhoid. If we make a section of the liver of a patient who has lied from a severe attack of typhoid fever, we shall, in a great number of cases, observe minute yellow points scattered at intervals throughout its substances, which seem almost like little uasses of tubercle.

If the section of such be examined under a No. 7 objective Harmach the lesion will be observed to be one of the middle zone, and to consist of a little round deposit, which stains rather more deeply than the surrounding tissue will picrocarnine, it seems to be almost entirely cellular, and although, to some extent, it resembles tubercle, yet in its microscopical characters it is quite different-the $d$-posit appears in every second or third lobule-they are formed by the breaking down of several of the liver cells by cloudy swelling, the first cbange noticed is that the periplast becomes extremely gianular, owing to the precipitation of the cellular albuminoids, which are normally h+ld iu solution by the natural alkalinity of the tissues. The origin of these changes is not quite determined, but it is supposed to be of an embolic character.

( $T o$ be continued.)

\section{PRACTICAL NOTES ON NEURALGIA AND ITS TREATMENT.}

\section{By REGINALD G. ALEXANDER, M.A, M.D. SENIOR PHYSICIAN TO THE GENERAL INFIRMARY, BRADFORD.}

THERE exists no better established nor important fact than that neuralgia is a disease arising when the body is in a state of general debility. This is now more generally reengnised than formerly, when pain was too often regarded as the symptom of what was termed "sthenic inflammation," to be energetically treated by low diet and clepleting remedies.

As this disease is frequently mistaken for rbemmatism. gout, spinal irritation, \&c., and vice ver's $\hat{a}$, it may be well to name some of the leading features of a typical case of neuralgia. 1. It occurs when general debility exists, is in creased by fatigue, mental or bodily, but relieved by food and sometimes by stimulants. 2. The pain, which is suddrn, darting, and excruciating exhibits remarkable intermis sions, especially in the early stages of the complaint, and the constitutional disturbance is slight (temperature, pulse, \&c., frequently normal). 3. It is usually unilateral. 4. As the disease advances tender spots (points douleurenx) aro formed in the course of the affected nerves.

That debility is a prime factor in neuralgia we bave but to call to our remenubrance cases which constantly appear. The overworked, anæmic, badly fed girl suffering from neuralgia of the fifth, the anxious struggling man in the early years of professional life or of business, the marned woman weakened by childbearing or over-zealous in domestic cares, and the neuralgia of declining years, de generation having set in, nutrition being defective. In our diagnosis we are assisted by the family history of the case, whether nervous disease in any of its varied forms has existed.

The treatment should be directed in every case toward improving the general health. Nutrition must be improved by very nourishing food, well masticated, and if stimulants are prescribed they should be given with food ; pure air night and day; great cleanliness, and the use of sponging with sea-salt and water. Cod-liver oil and cream are of service, given after meals. Quinine in facial neuralgias, and also chloride of ammonium ; arsenic in cases of angina pectoris; iron and strychnine in anæwic states. Bromide of potassium is useful in mild cases, where the pain is not severe, buta general nervous condition exists, with restless irritability The subcutaneous injection of morphia, beginning with one sixth of a grain, is the most speedy and useful remedy we possess, and is a curative agent ; for it checks at once pain. and thus gives us the opportunity of carrying out all those constitutional measures for improving the general health whilst it disturbs but little appetite and digestion, and with use a toleration is established, and appetite sometimes in. proved; for nothing is more apt to destroy appetite than the distress of severe pain. In chronic cases of neuralgia a blister, not necessarily carried to the point of vesication, is often of the greatest possible service, and it is a treatment peculiarly adapted to old.standing intractable cases.

Having sketched the mode of treatment it is unnecessary to give illustrations of the ordinary cases which constantly present themselves in hospital and private practice. ( therefore select from my note-book one of several successful cases where neuralgia has occurred in that period of life when a cure is rarely accomplished (some authorities say never) - the degenerative period.

In March, 1877, I saw, in consultation with Mr. Walker, 
of Wakefield, a lady aged seventy-six, who in early life had suffered severely from neuralgia of the stomach, which had been much aggravated by the treatment then in vogue of insufficient nutritive food and depleting remedies. This patient was seized with violent pain, affecting the nerves of the scalp, and which became so excruciating as to deprive her of sleep for many successive nights. She became delirious in consequence, and we decided to inject one quarter of a grain of morphia. This gave prompt relief and procured sleep. She was ordered turtle-soup, oysters, and an exceedingly nutritious dietary. She was well supplied with food at night also, which invariably relieved the pain. A mixture, con. taining half-drachm doses of aromatic spirit of ammonia and fifteen minims of tincture of nux vomica, seemed greatly to improve the appetite, which became prodigious and surprising. The tendency to degenerate was kept prominently in view, pure air was freely supplied in the bedroom, and every other measure taken to improve nutrition and the general health. As a local application, the chloroform liniment with tincture of opium relieved pain, and as soon as the case became chronic, the hair was cut closely and blistering fluid applied to the tender spots, which were well developed in this case; multiple abscesses formed, and were frequently opened by Mr. Walker. This old lady, after an illness of three months' severe suffering, recovered perfectly, left Wakefield for Harrogate, and is now (1882) in fair health, having had no return whatever of her former complaint. Her body is feeble, but her mind extraordinarily clear and bright for a lady who has passed her eighty-first year.

\section{ARTIFICIAL ERUPTION PRODUCED BY MECHANICAL MEANS.}

BY ALFRED SANGSTER, M.B., M.R.C.P.LOND., PHYSICIAN TO THE SKIN DEPARTMENT, CHARING-CROSS HOSPITAL. (From Notes by Mr. BAKER, late House-Physician.)

L. F_- a delicate, fair-haired girl, aged seventeen, presented herself at the out-patient department at Charing. cross Hospital with a peculiar and very disfiguring appearance of the face. Both cheeks were entirely covered by a thin, brownish, sharply defined, even incrustation, beyond which there was a broad hyperæmic border. On looking closely into the surface, many minute scattered hæmorrhagic points were seen. There was a large pigmented area on the neck, which the patient stated had been similarly affected. The appearances were not those of eczema or erythematous lupus, and indeed were so unusual that some questions were put to the stepmother, who accompanied the patient, as to whether she had any suspicion that the eruption was produced artificially. She, however, was quite surprised at the suggestion. All that could be elicited from the patient herself was that the face had "burnt" very much after exposure to cold wind, and that it presented the above-described appearance when she woke the following morning. She was admitted into the hospital.

From her history it appeared that she had good health until two years and a half ago, when she was laid up with an abscess in the ankle, the result of a sprain. Soon afterwards she had another abscess in the back, about the level of the second lumbar vertebra. The scars of these abscesses were quite conspicuous. Some deep scars on the left hand were accounted for by abscesses following a poisoned wound of the finger. There were some broad superficial scars on the extremities, which were 'said to have been left by patches such as those above described on the face. Some elongated excoriated patches were discovered corresponding to the position of the waistband.

During her stay in the hospital the patient frequently complained of sore-throat, which at these times seemed swollen externally about the thyroid cartilage. Several fresh patches made their appearance (during the night) while she was under observation, one on the left forearm, one at the bend of the left elbow, and a third over the sternal region. They were irregular in outline, those on the forearm and sternum three or tour inches in the longest measurement. All pre- sented the same initial heat and redness, with subsequent superficial incrustation and surrounding hyperæmia ; they ran a similar course, gradually fading, the crust falling in about ten days, leaving the part somewhat livid but nor scarred. Although the case was closely watched, and out suspicions concealed as much as possible, we were unable to prove how the patches were produced, at length it was decided to accuse the patient. Accordingly, Mr. Baker, the house-physician (to whom I am indebted for great interest taken in the case), having excoriated his arm by continued friction with the pulp of his fingers, taxed her with the deception. She confessed to having produced the patehes in the same way. She stated that she had not menstruated for two years, but that at the periods when the flow should have returned, red irritable patches used to appear on different parts of the body ; these she rubbed and excoriated, afterwards she found she could produce the patches at will, without any previous spontaneous reddening of the part. When she produced a patch on the site of an old one a superficial scar was left. The reason she gave for producing: the patches was that her life at home was unhappy, her father was a drunkard, she worked long hours, and had to give all her earnings to her stepmother, who was unkind to her.

Remarks.-Although the eruption was looked upon as artificial from the commencement there were one or two facts connected with it which gave it a certain reality, or, at least, called for explanation. It was astonishing that a young girl should so disfigure herself, even for a special purpose. However, it seems to be a fact that artificial eruptions are not unfrequently produced on the face presumably to enlist greater sympathy. The broad superficial scars, which she stated had been left by the eruption, suggested the employment of some chemical, such as those usually had recourse to. Yet the conditions under which the patient was placed whilst in the hospital rendered the concealment of any such substance almost impossible. The occurrence of patches in the region of the waistband hardly looked like design. The girl was rather cheerful and well-spoken; she was not hysterical, and, in the absence of assignable motive, would not have been suspected of fraud. The sequel proved, however, that she was overwrought, harshly dealt with, and probably in need of rest, which she could only obtain by feigning disease. There may have been truth in what was said about the amenorrhoea and the spontaneous red irritable patches; however, she did not mention this at first, and she menstruated while in the hospital. The case seems worthy of record as an example of the production of an artificial eruption by mechanical means, most artificial eruptions being due to the application of some chemical or irritant: nitric acid, cantharides, mustard, \&c.

\section{ACUTE PROLAPSUS OF RECTUM; SUGGES- TION AS TO TREATMENT.}

BY C. E. MACNAMARA, L.R.C.S.I, RESIDENT SURGEON TO THE PUBLIC HOSPITAL, GEORGE TOWN, BRITISH GUIANA.

Prolapsus RECTI of the above form is a hernia the reduction of which unquestionably is often, even to a skilful and patient surgeon, a matter of anxiety, and always to the conscious patient an operation of considerable pain. And I therefore think that any suggestion as to a mode of treating it in a manner which deprives it of these objections will be received gratefully by many surgeons. The following plan $I$ have found in many obstinate cases to have been speedily and uniformly successful. I may here, perhaps, be allowed to mention that when I was on leave and at home during 1879, I acquainted my father, Professor Rawdon Macnamara of Dublin, with the plan, and he, as Surgeon to the Meath Hospital, and also Surgeon to the Lock Hospital of that city, has had many opportunities of testing its value, and has reported favourably. With this excuse for touching upon a subject which has been written upon in articles by various authors, I will briefly state the mode of treatment. $A$ case in point may be acceptable.

A. $\mathrm{B}$ - was admitted into the Public Hospital under the 